\title{
LAMENESS AND UDDER HEALTH IN SWEDISH DAIRY HERDS, AS INFLUENCED BY HOUSING CHANGES
}

\author{
Jan Hultgren \\ Department of Animal Environment and Health, \\ Swedish University of Agricultural Sciences, Skara, Sweden
}

Traditionally, tie-stalls have been the predominant housing system for dairy cattle in northern Europe. In Sweden, tie-stalls are either long-stalls (approx. $2.20 \mathrm{~m}$ ) or short-stalls (approx. $1.70 \mathrm{~m}$ ). In long-stalls the cows are normally closed out from the feeding table when the herdsman is not in the barn, while in short-stalls they have always access to the feeding table. Loose housing has been recommended and increases with new facilities. Presently, one fourth of the Swedish dairy cows are loose-housed. Very few observational studies of possible animal health effects of a transition from one housing system to another have been performed. The aim of the present study was to assess effects of changes in housing system on the occurrence of veterinary-treated foot and leg disorders, clinical mastitis, teat injuries and of high milk somatic cell counts (MSCCs). The objective was to improve the basis for farmers' decisions in connection with structural changes in milk production. Monthly herd disease incidence rates or prevalences in 194 Swedish commercial dairy herds from 1988 to 1995 were collected retrospectively from the official milk recording scheme and merged with county administrative and farmers' data on housing and management. The studied herds constituted approximately one third of all dairy facilities approved for rebuilding in the selected counties during the same time period. The most common changes of housing systems were going from long-stalls to short-stalls (61 herds), remaining in short-stalls (41 herds) and going from short-stalls to cubicles (33 herds). Predominant breeds were the Swedish Red and White (SRB) and the Swedish Holstein breed (SLB). Mean herd size was 34.6 cows for long-stalls, 39.2 for short-stalls, 62.7 for cubicles and 55.8 for straw yards. The records were either from 1 to 45 months before building start (mean 10.7 months) or from 0 to 59 months after building finish (mean 11.4 months). All data from the actual building period were discarded. Four Poisson regression models were applied to the data (5982 to 7026 herd-month records), using the GEE method and the GENMOD procedure in SAS. Monthly observations were treated as repeated measures within herds (autoregressive correlation structure). There were significant transitory increases in the incidence of clinical foot/leg disorders when changing from tie-stalls to cubicles $(\mathrm{RR}=3.2-4.7)$ and decreases in the incidences of clinical mastitis $(\mathrm{R}=0.20-0.77)$ and teat injuries $(\mathrm{RR}=0.13-0.60)$ when changing from tie-stalls to loose housing. Effects on foot/leg health generally lasted for less than 18 months after building finish, while udder health improvements persisted beyond 18 months. Reductions in the incidence of clinical mastitis were not accompanied by any clear changes in the prevalence of high MSCCs. Later than 18 months after rebuilding, herds that shifted from long-stalls to short-stalls had less foot and leg lesions than those remaining in long-stalls.

It is concluded that a change in dairy cow housing from tie-stalls to loose housing deteriorates foot/leg health temporarily and improves udder health. 